\title{
The wing stalk in Diptera, with some notes on the higher-level phylogeny of the order
}

\author{
JAROSLAV STARÝ
}

\begin{abstract}
Department of Zoology and Laboratory of Ornithology, Faculty of Science of the Palacký University, tř. Svobody 26, 77146 Olomouc, Czech Republic; e-mail: stary@prfnw.upol.cz
\end{abstract}

Key words. Diptera, morphology, wing stalk, higher-level phylogeny

\begin{abstract}
The wing stalk in Diptera is examined, and its structures are re-evaluated and re-interpreted. The non-homology of $A_{2}$ in Tipulomorpha and " $\mathrm{A}_{2}$ " in other Diptera is claimed. Some notes are presented on the higher-level phylogeny of Diptera, especially those concerning Tipulomorpha. The family Trichoceridae is restored among Tipulomorpha, and the Tipulomorpha are re-affirmed as the sister group of the remaining Diptera. The clade Anisopodidae + Culicomorpha + Bibionomorpha is suggested as the sister group of Brachycera.
\end{abstract}

\section{INTRODUCTION}

Hennig (1968) published a comprehensive treatment of the evolution of the wing base in Diptera, i.e., the complex of features within the so-called wing stalk, mainly the reduction of $\mathrm{A}_{2}$ and the development of the alula. He concluded that $\mathrm{A}_{2}$ is reduced in Diptera other than Tipulomorpha and only retained as a more or less sclerotised, longitudinal cord separating the upper part of the wing stalk from the alula. He hypothesised that Tipulomorpha (Polyneura in his concept) is the sister group of all other Diptera (Oligoneura). He raised some doubts whether the fold, or vein, arising from the alular cord beyond the alular incision into the anal lobe in many Diptera, sometimes almost attaining the wing margin, should be termed $A_{2}$. Nevertheless, the view has generally been accepted that the "vein" posterior to $\mathrm{A}_{1}$, when present, is $\mathrm{A}_{2}$, and that it "ends before the wing margin in all Diptera except the Tipulidae and the Trichoceridae" (McAlpine, 1981: 33). Neither the alula, one of the major novelties in the evolution of the wing in Diptera, nor the associated structures, are included in recent phylogenetic analyses

The system adopted here for naming the veins is the socalled Comstock-Needham system, which recognizes the veins $\mathrm{Cu}(\mathrm{CuA}), \mathrm{A}_{1}$ and $\mathrm{A}_{2}$ in the cubito-anal field. This system is used for convenience since it is commonly applied to Diptera. On the other hand, the proposals by Wootton \& Ennos (1989) and, quite recently, by Saigusa (2006), homologising the dipteran $\mathrm{A}_{1}$ with the mecopteran $\mathrm{CuP}$, appear to be justified.

In the present paper, the wing stalk in Diptera is examined, and its structures are re-evaluated and re-interpreted. In light of this, it is claimed that the $\mathrm{A}_{2}$ in Tipulomorpha and " $\mathrm{A}_{2}$ " in other Diptera are not homologous, and some notes are presented on the higher-level phylogeny of Diptera.

Because of the quite different concepts used by different authors, some names given previously to the lower dipteran infraorders are not utilised here, especially Psy- chodomorpha, and particular taxa are treated at family level. The infraorders accepted are conceived here as follows: Tipulomorpha: Trichoceridae, Limoniidae, Pediciidae, Tipulidae, Cylindrotomidae; Culicomorpha: Simuliidae, Dixidae, Culicidae, Thaumaleidae, Ceratopogonidae, Chironomidae; Bibionomorpha: Cecidomyiidae, Bibionidae, Axymyiidae, Mycetophilidae s. lat., Sciaridae, Scatopsidae, Canthyloscelidae, Synneuridae. Some minor lower dipteran families could not be examined and are not considered here.

\section{THE WING STALK IN DIPTERA AND HOMOLOGY OF} $\mathbf{A}_{2}$

The examination of the wing stalk has revealed a transformation series with three character states for this complex of features. Whereas, in Tipulomorpha, as the first state, $\mathrm{A}_{2}$ is normally developed, attaining the hind margin of the wing at from one third to half the length of the wing (Fig. 2) (except in Trichoceridae where it is somewhat shortened apomorphically; Fig. 1), this vein is extremely shortened in all other Diptera. It can be traced in the wing stalk as a part of the vein pattern roughly reminiscent of a horizontal $\mathrm{T}$, with its upper branch formed by the cross-vein connecting $\mathrm{A}_{1}$ and $\mathrm{A}_{2}$ (a part of the so-called inner cord, or arculus, and called $\mathrm{a}-\mathrm{a})$, and its axis and lower branch represented just by $\mathrm{A}_{2}$ (cf. Figs 1, 2 and 3-5). This is the second state in the transformation series. Thus, $A_{2}$ is angulated at the connection with a-a and transverse distally. It should be especially emphasized that the shortened $\mathrm{A}_{2}$ does attain the hind margin of the wing stalk. From this, it clearly follows that any structure beyond the T-shaped pattern has nothing to do with the true $A_{2}$. The reduction of $A_{2}$ is hypothesised here, in accordance with Hennig (1968), although interpreted in a different way, as the first step in the evolution of the wing stalk in Diptera (see below in Discussion).

In contrast with Hennig (1968), I do not suppose that, simultaneously with the reduction in $\mathrm{A}_{2}$, the alula arose and the wing stalk was separated from the wing blade by 

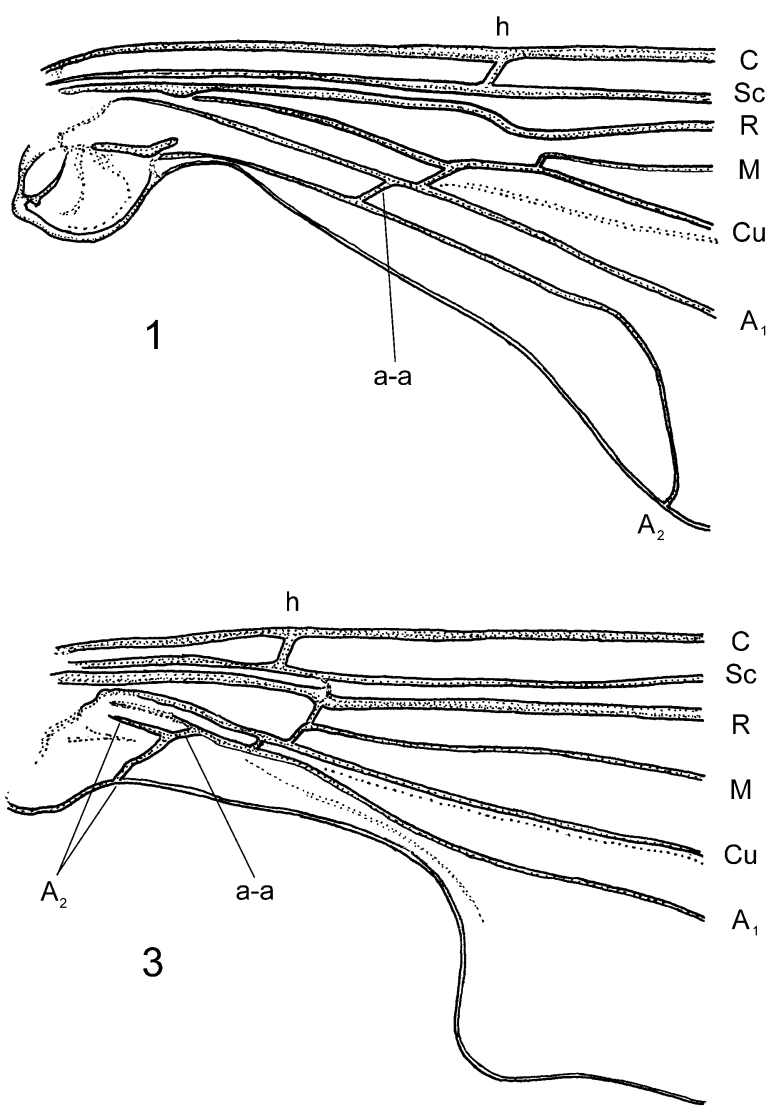
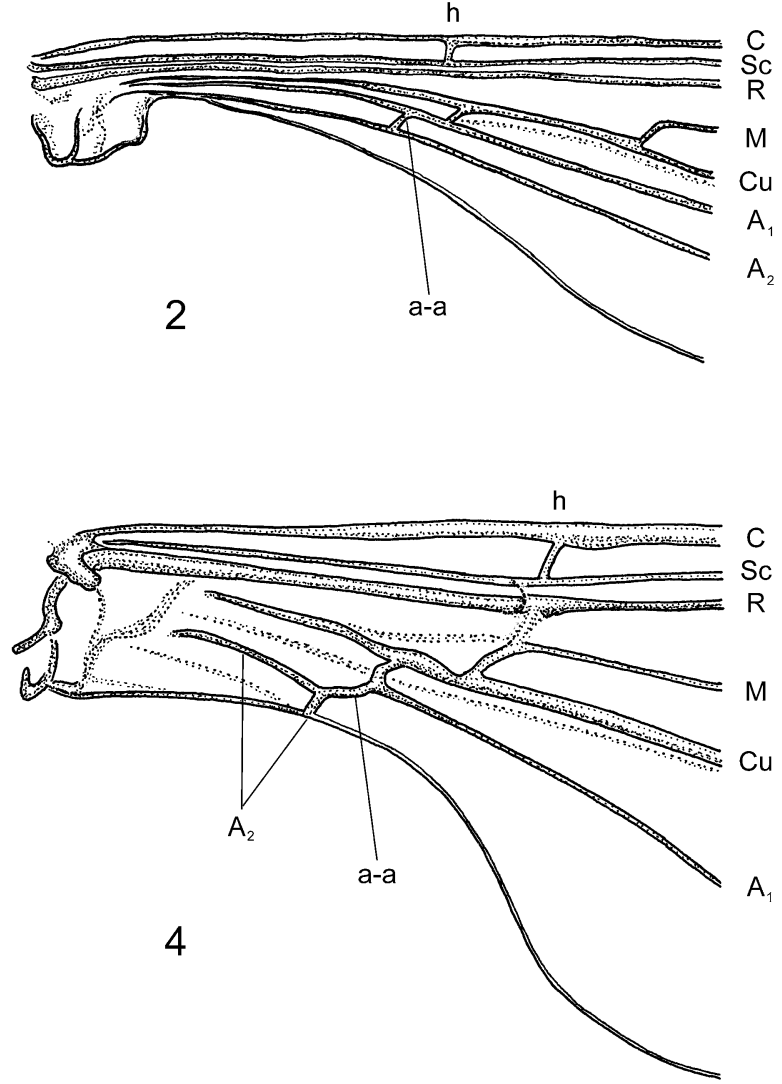

Figs 1-4. Wing stalk in Diptera. 1 - Trichocera (Trichocera) hiemalis (De Geer, 1776) (Trichoceridae); 2 - Austrolimnophila (Austrolimnophila) ochracea (Meigen, 1804) (Limoniidae); 3 - Protanyderus beckeri (Riedel, 1920) (Tanyderidae); 4 - Ptychoptera contaminata (Linnaeus, 1758) (Ptychopteridae). For details, see text.

the alular incision. In the families Tanyderidae, Ptychopteridae and Blephariceridae (for Blephariceridae, see in Discussion), $\mathrm{A}_{2}$ is extremely shortened, angulated, with its distal portion transverse, reaching the hind margin of the wing stalk (Figs 3-5), the wing stalk itself, however, is not yet separated from the wing blade by an incision. The angle at the base of a considerably protruding anal lobe in Tanyderidae and Blephariceridae (Figs 3, 5) does not seem to be a precursor, or rudiment, of the alular incision. A similar, considerably protruding anal lobe is also present e.g. in the genus Antocha of Limoniidae. According to the present interpretation, the wing stalk passes gradually into the wing blade in Tanyderidae, Ptychopteridae and Blephariceridae, as it does in Tipulomorpha, whereas, in Hennig's (1968) concept, the condition, at least that in the Ptychopteridae, is interpreted as a result of a secondary reduction. The angle at the base of the anal lobe is situated markedly beyond the humeral cross-vein (Figs 3, 5, h), whereas the alular incision normally is observed opposite that vein (Figs 6-9). A slight fold, present in some Tanyderidae and Blephariceridae in the vicinity of the anal angle (Figs 3,5), seems to have been acquired as a consequence of the tension in the protruding anal lobe, most probably independently in the two families, and independent of the development of the alula.

An essential modification of the wing stalk comes only with the third character state. The wing stalk becomes broader at the hind margin, expanded and rounded, pro- ducing the alula. An incision (alular incision, alinc) arises close to the level of the humeral cross-vein, sharply separating the wing stalk from the wing blade. The T-shaped vein pattern is pushed still more proximally, so that $A_{2}$ reaches the wing margin between the squama and the alula. Simultaneously, a more or less sclerotised, longitudinal cord is developed in the wing membrane, sometimes indistinct, yet observable at high magnification, separating the alula from the upper part of the wing stalk and reaching the alular incision (Figs 6-9). This structure, termed here the alular impression (alimp), was interpreted as a rudiment of $A_{2}$ by Hennig (1968), but cannot be that for the reasons presented above. The alular impression is an evolutionary novelty correlated with the development of the alula. It makes it possible for the alula to be tilted upwards relative to the remaining wing area (cf. Hennig, 1968: 10). As a continuation of the alular impression, a more or less sclerotised fold appears distal of the alular incision, extending into the anal lobe of the wing (Figs $8-9$ ), perhaps as a consequence of the tension in the anal lobe, caused by the development of the alula (cf. Hennig, 1968: 9). Sometimes several such folds are observed (Fig. 6). This fold, which sometimes takes the appearance of a vein, has been quite universally misinterpreted as $\mathrm{A}_{2}$, although doubted as such early on by Hennig (1968). The true $A_{2}$, however, if not obscured by further evolution, attains the hind margin of the wing stalk between the squama and the alula, as emphasised above (cf. Figs 6-9). 

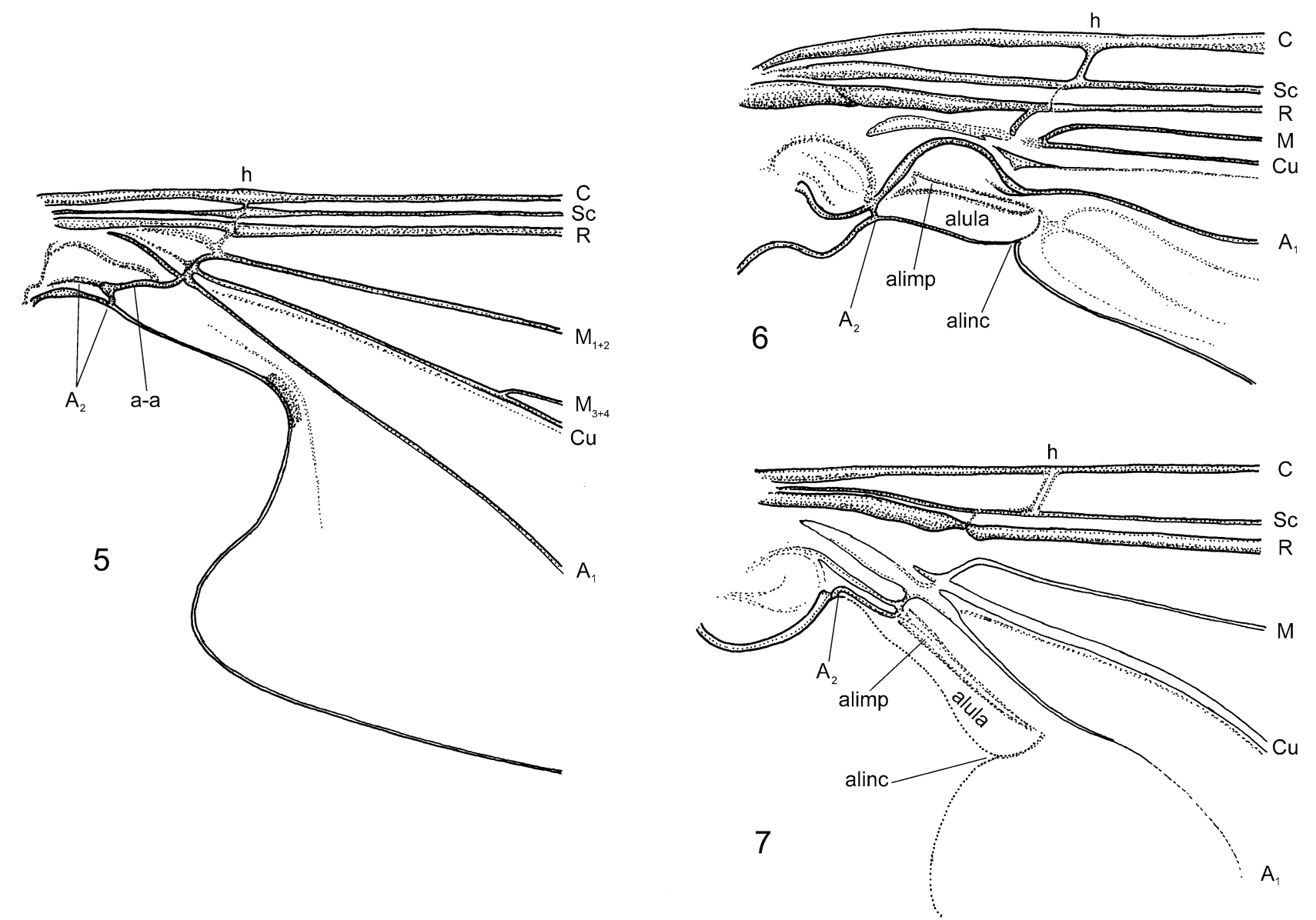

Figs 5-7. Wing stalk in Diptera. 5 - Liponeura cinerascens minor Bischoff, 1922 (Blephariceridae); 6 - Culiseta (Culiseta) alaskaensis (Ludlow, 1906) (Culicidae); 7 - Bibio hortulanus (Linnaeus, 1758) (Bibionidae). alimp - alular impression; alinc - alular incision. For details, see text.

Hence, this fold is another evolutionary novelty correlated with the development of the alula, and is here called the alular fold (Figs 8-9, Af). The wing base is further modified in Brachycera (e.g. differentiation of two calypteres), but the situation shown in Figs 8-9 remains, in the ground plan, more or less identical up to Muscomorpha (McAlpine, 1981, Figs 68-69 and many other more or less detailed figures in the Manual of Nearctic Diptera and elsewhere).

An alternative is not accepted that the transverse element considered here to be the distal section of $\mathrm{A}_{2}$ is the cross-vein connecting $\mathrm{A}_{2}$ and $\mathrm{A}_{3}$ in Mecoptera (or a combined rudiment of this cross-vein and $\mathrm{A}_{3}$ ), and that, hence, the alular impression and the alular fold still may be homologous with $\mathrm{A}_{2}$. Whereas, in Tipulomorpha, $\mathrm{A}_{2}$ is distinctly convex through all its course (see also Hennig, 1954, Fig. 5), both the alular impression and the alular fold, when present, are concave (the latter also indicated by McAlpine, 1981, Fig. 68).

\section{DISCUSSION}

Based on the above examination, the discussion is presented here of some aspects of the higher-level phylogeny of Diptera. The concepts proposed by Michelsen (1996, Fig. 24) and Krzemiński \& Krzemińska (2003, Fig. 2) are used as guidelines. The two hypotheses accord rather well with the development of the alula, as outlined herewith. Two recent and well-known cladograms, viz. by Wood \& Borkent (1989) and Oosterbroek \& Courtney (1995), appear less reliable because of some unusual arrangements. In the cladogram by Wood \& Borkent (1989), the family Trichoceridae was separated from the rest of Tipulomorpha and included in the largely polyphyletic "Psychodomorpha". Moreover, the Nematocera were regarded as a monophyletic group. In the cladogram by Oosterbroek \& Courtney (1995), the Trichoceridae, admittedly, were included with Tipulomorpha, but the latter were placed among the so-called "higher Nematocera" as the sister group of the clade Anisopodidae + Brachycera. According to both cladograms, which otherwise are rather different in many aspects, the alula, with identical structural equipment, must have been acquired independently at least five times.

\section{General aspects}

Since Hennig (1954) there has been little disagreement over the ground-plan venation of Diptera. This was interpreted as having five radial veins attaining the wing margin and a well-developed $\mathrm{A}_{2}$, likewise attaining the wing margin (cf., e.g., Hennig, 1954, Fig. 5; McAlpine, 1981, Fig. 67). This concept is accepted here. The tipulomorphans possess a well-developed $\mathrm{A}_{2}$, but are apomor- 

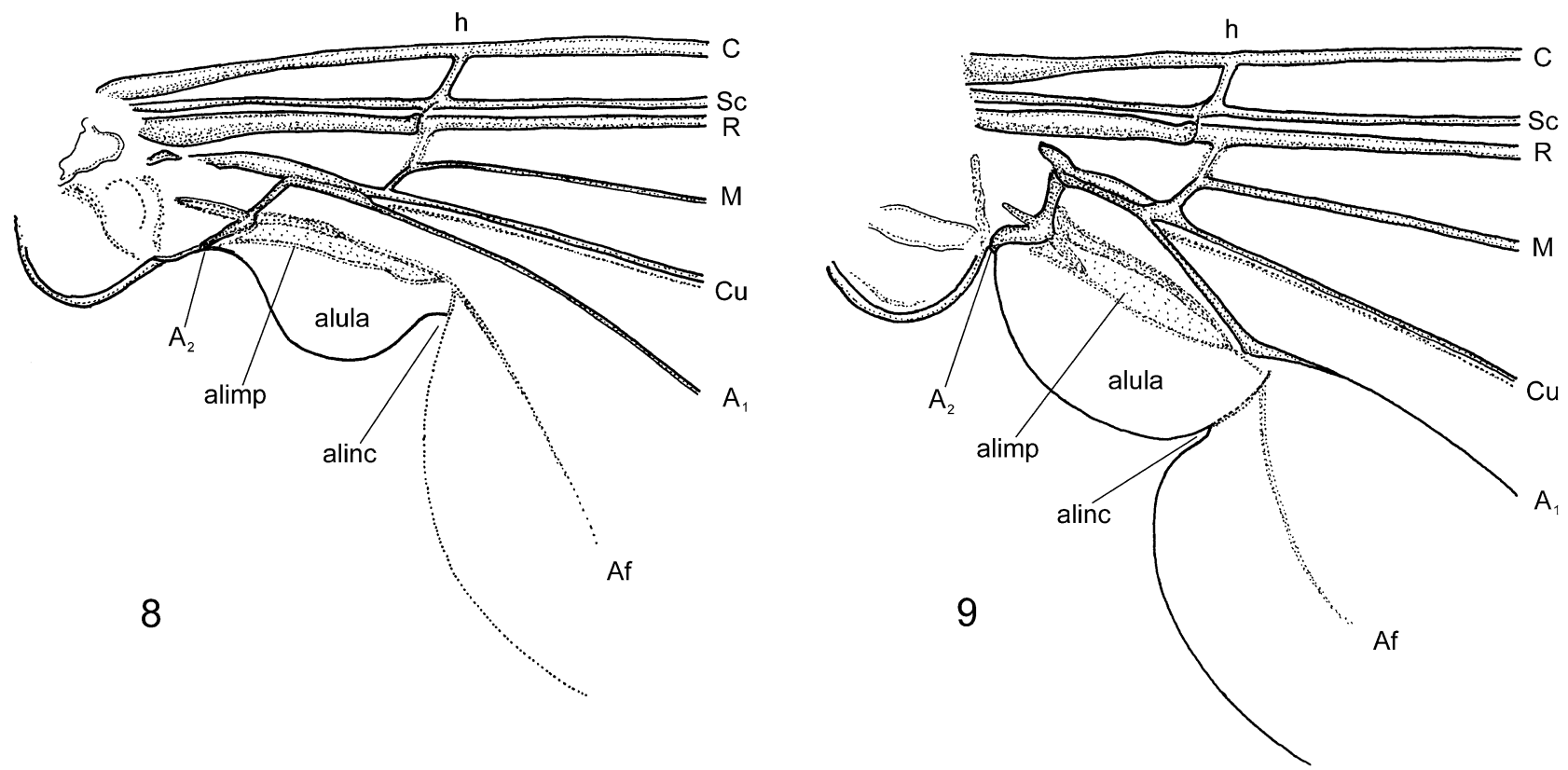

Figs 8-9. Wing stalk in Diptera. 8 - Sylvicola sp. (Anisopodidae); 9 - Ibisia marginata (Fabricius, 1781) (Athericidae). Af alular fold; alimp - alular impression; alinc - alular incision. For details, see text.

phic in that $R_{2}$ is transverse and connected to $R_{1}$. By contrast, in the remaining Diptera, including the families where five separate radial veins attain the wing margin, viz. Tanyderidae and Psychodidae, $\mathrm{A}_{2}$ is reduced.

As an exception, Krzemiński's hypothesis (Krzemiński, 1992; Krzemiński \& Krzemińska, 2003) claimed that the ground plan for a well-developed $\mathrm{A}_{2}$ was the so-called anal loop, or anal ring, a vein pattern present at the base of the wing in Grauvogelia arzvilleriana (Lower/Middle Triassic of France), which was proclaimed as the hitherto oldest dipteran. Hence, based on that concept, the long $\mathrm{A}_{2}$ is considered to be a synapomorphy of Tipulomorpha. To a certain degree, Krzemiński's hypothesis is right in that, from the anal loop, a term originally restricted to Grauvogelia arzvilleriana (cf. Krzemiński et al., 1994), but later (Krzemiński \& Krzemińska, 2003) apparently extended to include the conditions in many other fossil and extant Diptera, and also those described here for Tanyderidae and Ptychopteridae (Figs 3-4), a fold evolved, interpreted here as the alular fold (Af). This structure, however, has nothing to do with the $\mathrm{A}_{2}$ in Tipulomorpha.

\section{The higher-level phylogeny of Diptera}

The present examination of the wing stalk suggests that the reduced $A_{2}$ represents a synapomorphy for all the Diptera other than Tipulomorpha. This automatically means that Tipulomorpha, with $\mathrm{A}_{2}$ retained as a long vein, should be placed at the base of the dipteran cladogram, which is in agreement with previous prevailing views.

The monophyly of Tipulomorpha is well established by the following synapomorphies [for details, especially those analysing the arguments which Wood \& Borkent (1989) gave in support of their separation of Trichoceridae from Tipulomorpha, see Starý, 1992] (Fig. 10, characters $1-4)$ :
1. All branching points of longitudinal veins occur distally. This character state appears rather relative, but a comparison of various venational patterns within and outside Tipulomorpha offers strong support. In Tipulomorpha, the branching points of longitudinal veins are shifted distinctly more distally in comparison with both the ground plan of Diptera and the condition in the representatives of non-tipulomorphan families. It should be

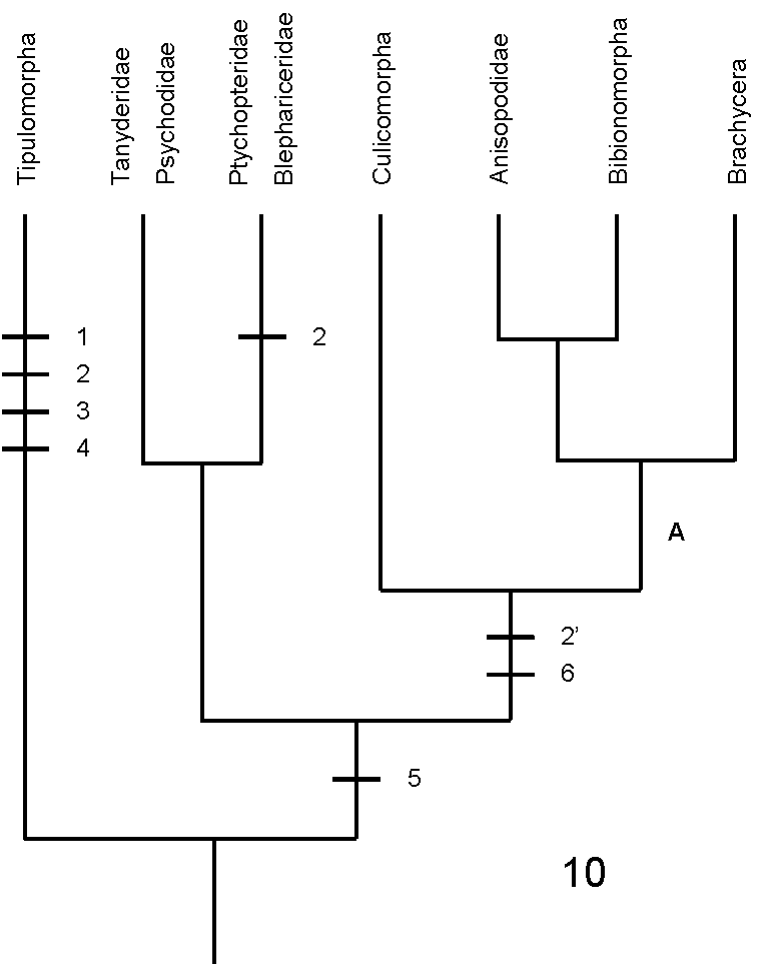

Figs 10. Alternative cladogram of the higher-level phylogeny of Diptera. A - Neodiptera (sensu Michelsen, 1996). The numbers refer to the characters described in the text. 


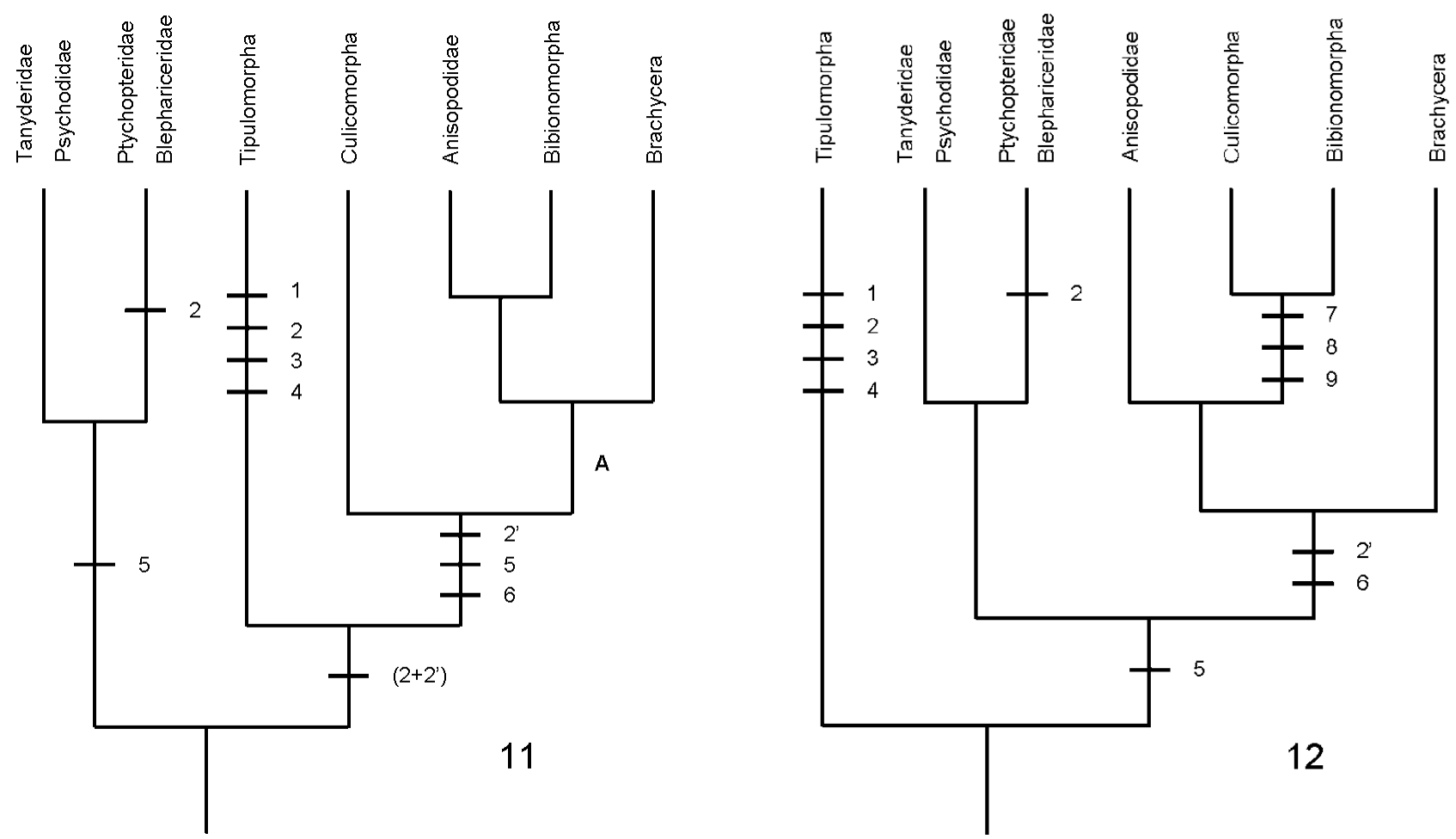

Figs 11-12. Alternative cladograms of the higher-level phylogeny of Diptera. A - Neodiptera (sensu Michelsen, 1996). The numbers refer to the characters described in the text.

emphasized that only branching points are considered, not the connections of longitudinal veins with the costa, which, by contrast, tend to be shifted proximally.

2. Vein $R_{2}$ fused with $R_{1}$ distally, not reaching wing margin as a separate vein. Vein $R_{2}$, in the ground plan of Tipulomorpha, is transverse, connecting $\mathrm{R}_{3}$ with $\mathrm{R}_{1}$ [socalled cephalisation of $R_{2}$ (Alexander, 1927), cf. also Starý, 1992]. Formerly, it was called a cross-vein r. This character state is only paralleled by Ptychopteridae. The transverse $\mathrm{R}_{2}$ lacks macrotrichia, but a detailed examination of the wing venation revealed that the macrotrichia tend to atrophy on all transverse vein elements. As a support for the correct interpretation of $\mathrm{R}_{2}$ in Tipulomorpha it should be mentioned that once the transverse $R_{2}$ atrophied, which frequently occurred (e.g. in some eriopterine Limoniidae), an analogous process of cephalisation is observed in the next longitudinal vein, namely $\mathrm{R}_{3}$ (e.g. Atarba and Idiocera of Limoniidae).

3 . Wing base strongly narrowed. This character state is distinct from that in both other Diptera (cf. Figs 1-2 and 3-5) and Mecoptera.

4. Veins $\mathrm{M}, \mathrm{M}_{3+4}$ and $\mathrm{M}_{4}$ are aligned (discal cell above M stem).

The reduction of $\mathrm{A}_{2}$, described above as the second character state in the transformation series, is presumed to be the first step in the evolution of the wing stalk and a synapomorphy for all the Diptera other than Tipulomorpha (Fig. 10, character 5).

5. $\mathrm{A}_{2}$ extremely shortened, angulated, with its distal portion transverse, reaching the hind margin of the wing stalk (Figs 3-5). The shortening (proximalisation) of $\mathrm{A}_{2}$ coincides well with the principal tendencies in the evolu- tion of the wing venation in Diptera (Starý, 1992). The angulated nature of the shortened $\mathrm{A}_{2}$ is caused by crossvein a-a. The latter is even more or less oblique in position as if drawn rearwards by the retracting $\mathrm{A}_{2}$ (Figs 3-5). A similar phenomenon of angulation occurs in other veins throughout Diptera (radial veins in Tipulidae, $\mathrm{Cu}$ in some Trentepohlia of Limoniidae and many Brachycera, etc.). It should be noted that the loss, or reduction, of $\mathrm{A}_{2}$ in Doaneomyia (Limoniidae) and Stibadocerella (Cylindrotomidae) represent comparatively recent homoplasies.

The phylogeny of the families Tanyderidae, Ptychopteridae and Blephariceridae is interpreted here based on Krzemiński \& Krzemińska (2003), i.e., the Psychodidae (whose wing base morphology has not been resolved by me) was added, and the group is introduced as a monophyletic unit, with the sister groups Tanyderidae + Psychodidae and Ptychopteridae + Blephariceridae (Fig. 10) (but see in Alternatives).

The development of the alula is presumed to be the second step in the evolution of the dipteran wing stalk. This complex of characters is considered here to be a strong apomorphy. Based on this, all the remaining Diptera, i.e. Culicomorpha, Anisopodidae, Bibionomorpha and Brachycera, differ from both Tipulomorpha and the "pre-alular" families Tanyderidae, Psychodidae, Ptychopteridae and Blephariceridae, and are considered here a monophyletic group (Fig. 10, character 6).

6. Alula developed (Figs 6-9). The alula is characterized by the presence of the alular impression (alimp), the alular incision (alinc) opposite the humeral cross-vein (h), and it is often accompanied by an alular fold (Af). The alula and associated structures may be secondarily modi- 
fied, reduced or even lost, the relationship of particular taxa, however, can be inferred from other characters. Attention should be drawn to the somewhat expanded wing stalk in some Blephariceridae, with a lobe reminiscent of a low alula (Hogue, 1981, Fig. 3). This structure does not have an alular impression, and appears to be extended beyond the humeral cross-vein, yet it might represent a rudiment of the alula.

To summarise, the phylogeny of the Diptera is suggested in Fig. 10. Two aspects should be especially emphasised in support of the previous views: (1) The family Trichoceridae is clearly a part of Tipulomorpha, and (2) Tipulomorpha (along with the Trichoceridae) are considered the sister group of the remaining Diptera.

\section{Alternatives}

The wing venation of the family Tanyderidae is often presented as the most primitive within the extant Diptera (Krzemiński, 1992; cf. also citations in Oosterbroek \& Courtney, 1995, etc.), and it even became a model for the dipteran ground plan (Hennig, 1954, Fig. 5; McAlpine, 1981, Fig. 67). Consequently, the Tanyderidae, possibly with some other families, were sometimes placed at the base of the dipteran cladogram. This concept cannot be discounted. This alternative arrangement, converted from the cladogram in Fig. 10, is given in Fig. 11. In fact, in terms of the longitudinal veins, Tanyderidae are as primitive as Tipulomorpha, namely with one longitudinal vein reduced, $\mathrm{A}_{2}$ in Tanyderidae and $\mathrm{R}_{2}$ in Tipulomorpha. If Tipulomorpha are to be considered the sister group of the remaining Diptera, the reduction of $\mathrm{A}_{2}$ is presumed to have occurred once, and the reduction (verticalisation) of $\mathrm{R}_{2}$ three times (for Tipulomorpha, Ptychopteridae + Blephariceridae and Culicomorpha et al.) (Fig. 10, characters 5 and 2 respectively, including 2'). If Tanyderidae (et al.) are to be considered the sister group of the remaining Diptera, the reduction of $\mathrm{A}_{2}$ must have occurred twice (for Tanyderidae et al. and Culicomorpha et al.), and that of $\mathrm{R}_{2}$ also twice (for Ptychopteridae + Blephariceridae and Tipulomorpha + Culicomorpha et al.) (Fig. 11, characters 5 and 2 respectively, including 2'). Thus, four steps are necessary for both alternatives. $\mathrm{R}_{2}$, in the ground plan, is transverse in Tipulomorpha (and Ptychopteridae), retained as a cross-vein linking $\mathrm{R}_{3}$ with $\mathrm{R}_{1}$, and may be eventually entirely lost in some more apomorphic tipulomorphan taxa. In Culicomorpha et al., $\mathrm{R}_{2}$ is consistently absent. This loss, however, may not have necessarily passed through the state known in Tipulomorpha (and Ptychopteridae). Hence, the absence of $\mathrm{R}_{2}$ in Culicomorpha et al. may be a result of a different evolutionary trend, and thus a different character (Figs 10-11, character 2'). This favours the pattern with Tipulomorpha as the basal lineage of Diptera, which is more parsimonious (Fig. 10).

Michelsen (1996) presented a detailed study of the skeleto-muscular organisation of the adult prothorax and cervix, and established Neodiptera as a monophyletic group. This clade includes Bibionomorpha, including Anisopodidae, and Brachycera, but not Culicomorpha. Both the cladograms in Figs 10 and 11 are in accordance with the concept of Neodiptera (indicated A therein). Based on the present study of the wing stalk, an alternative scheme is presented. The clade including Anisopodidae, Culicomorpha, Bibionomorpha and Brachycera is considered monophyletic, with the sister groups Anisopodidae + (Culicomorpha + Bibionomorpha) and Brachycera (Fig. 12). The concept with Anisopodidae alone as the sister group of Brachycera was proposed by Woodley (1989) and Oosterbroek \& Courtney (1995), based on the similarity of the Anisopodidae to the lower Brachycera, especially in venation. It appears, however, that as in Brachycera, various modifications are likely to have occurred also in the sister group, in which ancestors of Anisopodidae gave rise to Culicomorpha and Bibionomorpha.

The monophyly of the clade Culicomorpha + Bibionomorpha is supported by the following synapomorphies (Fig. 12, characters 7-9):

7. Alula reduced (Figs 6-7). Compared to the state in the Anisopodidae, the alula is reduced in Culicomorpha and Bibionomorpha, which possess, however, in the ground plan, all the associated structures.

8. Eyes reniform, sometimes narrowly connected by an eye bridge. This character is considered here to be a strong synapomorphy, being only paralleled by Psychodidae. It is not consistently pronounced in Mycetophilidae s. lat. (reversal), but the latter is united with Sciaridae by other characters.

9. Discal cell absent. Although this character is weak, varying even within a genus in, e.g., Limoniidae, it is consistent in the clade.

Whereas the Tipulomorpha, as conceived here, clearly represents a monophyletic group, and the clade containing Anisopodidae, Culicomorpha, Bibionomorpha and Brachycera is well established based on the alula, the Tanyderidae, Psychodidae, Ptychopteridae and Blephariceridae, although associated here in a monophyletic group of "pre-alular" families (Figs 10-12), appear to be a somewhat questionable assemblage. It cannot be excluded that some, or all, of these families may prove to form lineages of their own branching off from the main stem, producing thus a comb cladogram, with Blephariceridae possibly even placed among the alular taxa. However, at present, insufficient evidence prevents the presentation of additional schemes.

With the reservations discussed above, the concept in Fig. 12 is preferred. If evolution did not occur in this way, it occurred in a different way. What we know is that it did occur.

ACKNOWLEDGEMENTS. I thank J. K. Gelhaus (Academy of Natural Sciences, Philadelphia, USA) for his helpful comments on the manuscript and revision of the English text. This study was supported by grant MSM6198959212. I also thank W. Krzemiński (Institute of Systematics and Evolution of Animals, Kraków, Poland) and one anonymous reviewer for their comments.

\section{REFERENCES}

Alexander C.P. 1927: The interpretation of the radial field of the wing in the nematocerous Diptera, with special reference 
to the Tipulidae. Proc. Linn. Soc. New South Wales 52: $42-72$.

HenNIG W. 1954: Flügelgeäder und System der Dipteren unter Berücksichtigung der aus dem Mesozoicum beschriebenen Fossilien. Beitr. Entomol. (Berlin) 4: 17-388.

HeNNIG W. 1968: Kritische Bemerkungen über den Bau der Flügelwurzel bei den Dipteren und die Frage nach der Monophylie der Nematocera. Stuttg. Beitr. Naturk. 193: 1-23.

Hogue C.L. 1981: Blephariceridae. In McAlpine J.F., Peterson B.V., Shewell G.E., Teskey H.J., Vockeroth J.R. \& Wood D.M. (eds): Manual of Nearctic Diptera. Vol. 1. Research Branch, Agriculture Canada, Ottawa, Monograph No. 27, pp. 191-197.

KRZEMIŃsKi W. 1992: Triassic and Lower Jurassic stage of Diptera evolution. Mitt. Schweiz. Entomol. Ges. 65: 39-59.

KRZEMIŃsKi W. \& KRZEMiŃSKA E. 2003: Triassic Diptera: descriptions, revisions and phylogenetic relations. Acta Zool. Cracov. (Suppl. - Fossil Insects) 46: 153-184.

Krzemiński W., KrzemińsKa E. \& PAPIER F. 1994: Grauvogelia arzvilleriana sp. n. - the oldest Diptera species (Lower/ Middle Triassic of France). Acta Zool. Cracov. 37: 95-99.

McAlpine J.F. 1981: Morphology and terminology - adults. In McAlpine J.F., Peterson B.V., Shewell G.E., Teskey H.J., Vockeroth J.R. \& Wood D.M. (eds): Manual of Nearctic Diptera. Vol. 1. Research Branch, Agriculture Canada, Ottawa, Monograph No. 27, pp. 9-63.
Michelsen V. 1996: Neodiptera: New insights into the adult morphology and higher level phylogeny of Diptera (Insecta). Zool. J. Linn. Soc. 117: 71-102.

Oosterbroek P. \& Courtney G. 1995: Phylogeny of the nematocerous families of Diptera (Insecta). Zool. J. Linn. Soc. 115: 267-311.

Saigusa T. 2006: Homology of Wing Venation of Diptera. A handout distributed at the $6^{\text {th }}$ International Congress of Dipterology, Fukuoka, Japan, 26 pp.

StARÝ J. 1992: Phylogeny and classification of Tipulomorpha, with special emphasis on the family Limoniidae. Acta Zool. Cracov. 35: 11-36.

Wood D.M. \& Borkent A. 1989: Phylogeny and classification of the Nematocera. In McAlpine J.F. \& Wood D.M. (eds): Manual of Nearctic Diptera. Vol. 3. Research Branch, Agriculture Canada, Ottawa, Monograph No. 32, pp. 1333-1370.

Woodley N.E. 1989: Phylogeny and classification of the "orthorrhaphous" Brachycera. In McAlpine J.F. \& Wood D.M. (eds): Manual of Nearctic Diptera. Vol. 3. Research Branch, Agriculture Canada, Ottawa, Monograph No. 32, pp. 1371-1395.

Wootton R.J. \& EnNos A.R. 1989: The implications of function on the origin and homologies of the dipterous wing. Syst. Entomol. 14: 507-520.

Received February 16, 2007; revised and accepted July 11, 2007 